\title{
The Warming Hive: Building Community, One Inflation at a Time
}

\author{
WHITNEY MOON \\ University of Wisconsin - Milwaukee
}

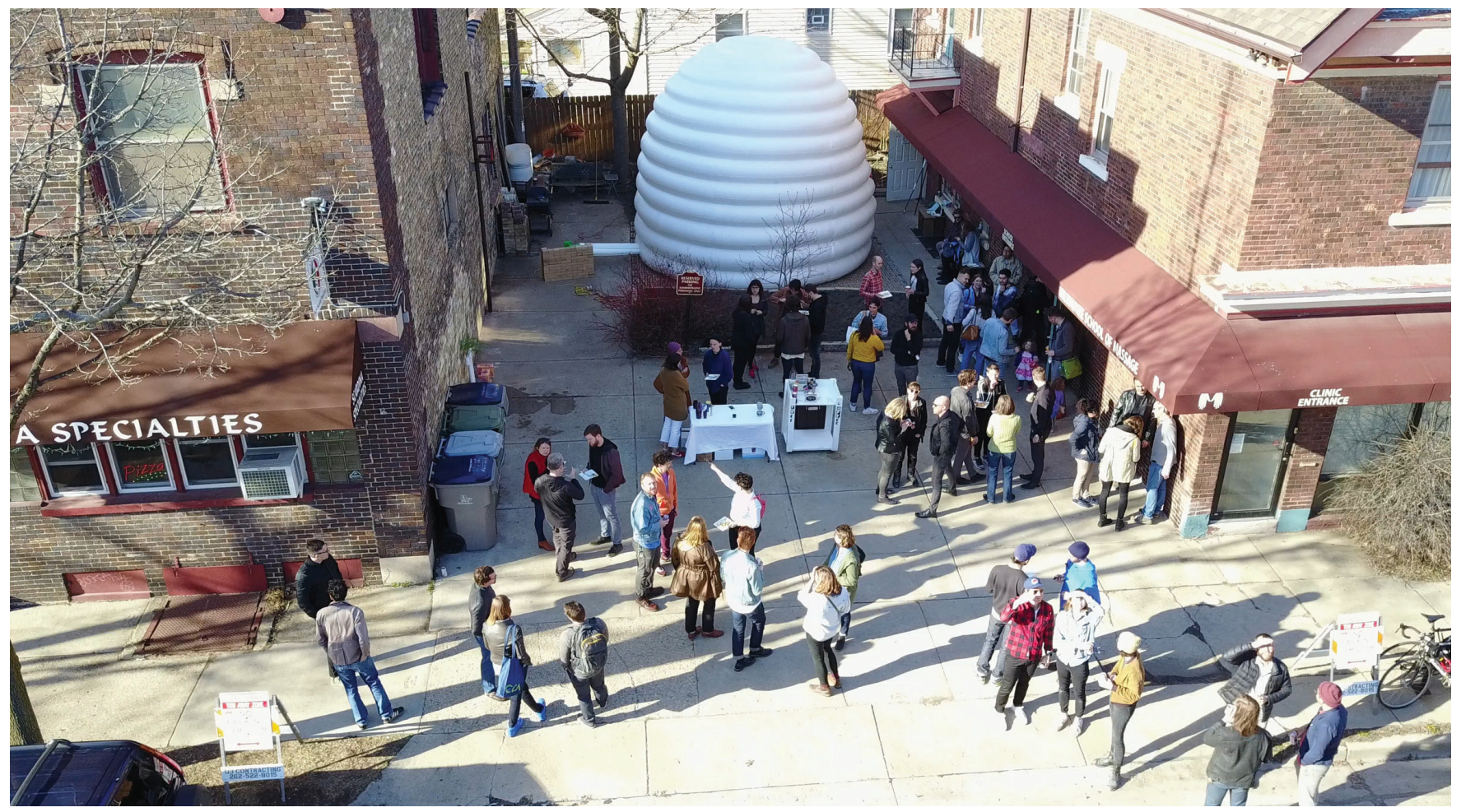

Figure 1: Premier installation of The Warming Hive during a gallery opening at The Open in Riverwest, Milwaukee on April 1, 2017. The Oven, which is located behind the The Warming Hive, provided thermal comfort inside the inflatable as well as hosted local Chef Peter Sandroni who cooked up a variety of dishes for the community event on a chilly afternoon. Photo courtesy of Davis Dolson.

Is it possible for an architectural space that can be used by anyone, to happen anywhere, anytime? This paper explores how pneumatic (a.k.a. inflatable) architecture can be deployed to address social resilience on a multiplicity of levels. Focusing on The Warming Hive-a recently completed pneumatic enclosure designed by architecture students at the University of Wisconsin-Milwaukee-this study challenges a common misconception that social resilience in architecture is limited to disaster relief. As evidenced by The Warming Hive, pneumatic architecture can generate new forms of social resilience, whereby communities are built though social engagement, one inflation at a time.

\section{THE PREMISE}

What role can architecture play in addressing social resilience? The social, political, environmental, and economic changes that each community deals with presents a constantly shifting set of programmatic demands and desires. In the construction (and reconstruction) of urban identity, architecture has agency through placemaking. Through the creation of public spaces, placemaking fosters community interaction and well-being. Yet, there are many financial and regulation-based obstacles to implementing change at the urban scale. In recent years, a trend towards tactical urbanism has emerged. Often ad hoc, do-it-yourself (DIY), or grassroots in nature, tactical strategies of placemaking are typically defined by temporary and lowcost transformations of the built environment. The intentions of both placemaking and tactical urbanism are to improve neighborhood conditions, with the objective to attract and engage participants. The latter model offers an expedient and flexible alternative to more permanent interventions-often serving as a test-case or prototype for subsequent changes to the built environment.

The perceived value of temporary transformations of the urban fabric is not only a contemporary phenomenon, but occupies a deep history in architectural discourse. From touring theatrical productions and circuses to festivals and world's fairs, temporary and mobile constructions have catered to the shifting demands of time, location, and 


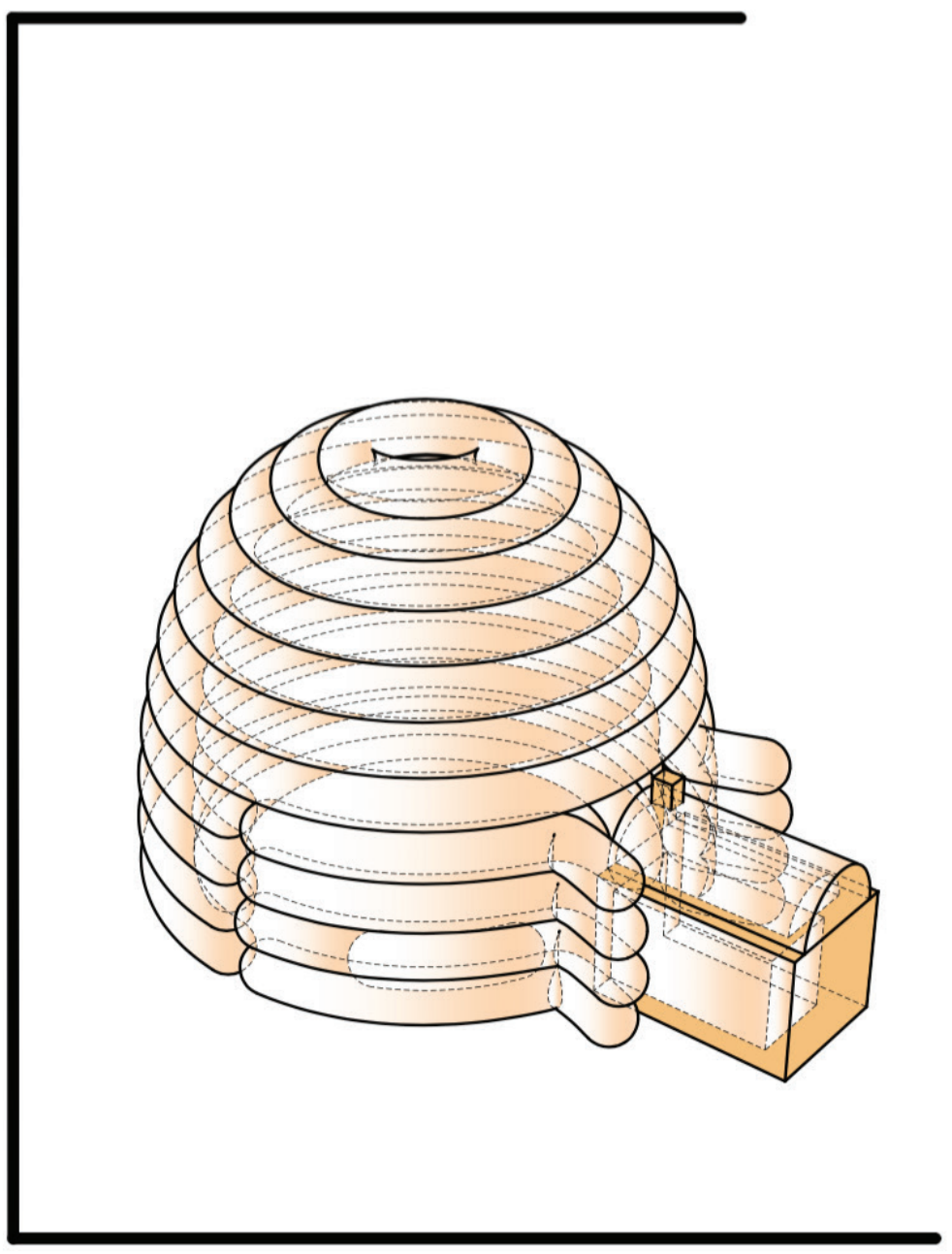

AXONOMETRIC

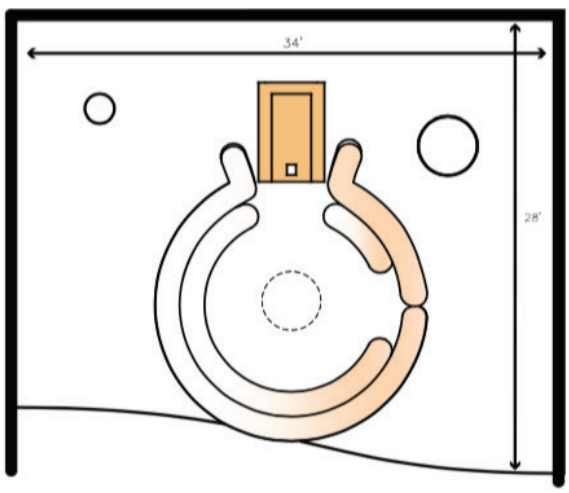

PLAN

Figure 2: The Warming Hive was designed by the eleven undergraduate and graduate architecture students of ARCH 533: Pillow Talk "Blow Up!" at UWM-SARUP in Fall 2016, taught by Assistant Professor Whitney Moon, PhD, RA, in collaboration with local artists Nicholas Frank (Nicholas Frank Public Library), John Riepenhoff (The Oven \& Green Gallery), \& Katy Cowan (The Outlet). Drawings courtesy of Jordan Nelson.

audience. These ephemeral, event-based architectures employ spectacle as a means to both communicate and entertain. They also serve as opportunities for architecture to redefine itself through alternative modes of expression. That is, the transient nature of these event-based constructions presents a host of technical and social challenges through which architecture can transform itself. Demands for expediency, lightness, durability, affordability, and flexibility encourage creative problem solving. The experimental nature of these provisional architectures, whereby new materials and construction methods are often employed, encourages (if not necessitates) innovation.

According to the late British architect Cedric Price, "The value of permanence must be proven not merely assumed." An advocate for temporary, lightweight, and flexible architecture, Price was also a leading figure in the research and development of pneumatic architecture in the 1960s and 70s. Dedicated to exploring the potential of structuring air as both a technical and social project, Price was drawn to pneumatics because they were an efficient, effective, and economical means by which to enclose and/or define space. Importantly, pneumatics also offered the opportunity to eschew architecture's conventional relationship with permanence. That is, the near-instantaneity of inflating a building also meant that it didn't need to be around for longer than its intended use. Responding to a cultural fascination with expendability (or a throw-away society) at the time, the perceived disposability of paper and plastic products urged architects like Price to consider alternative modes for constructing environments.

Price believed architecture had an expiration date. An advocate for impermanence, he was concerned with the possibilities that architecture produced, rather than an obsession with buildings proper. Because he was an advocate for the temporary and 


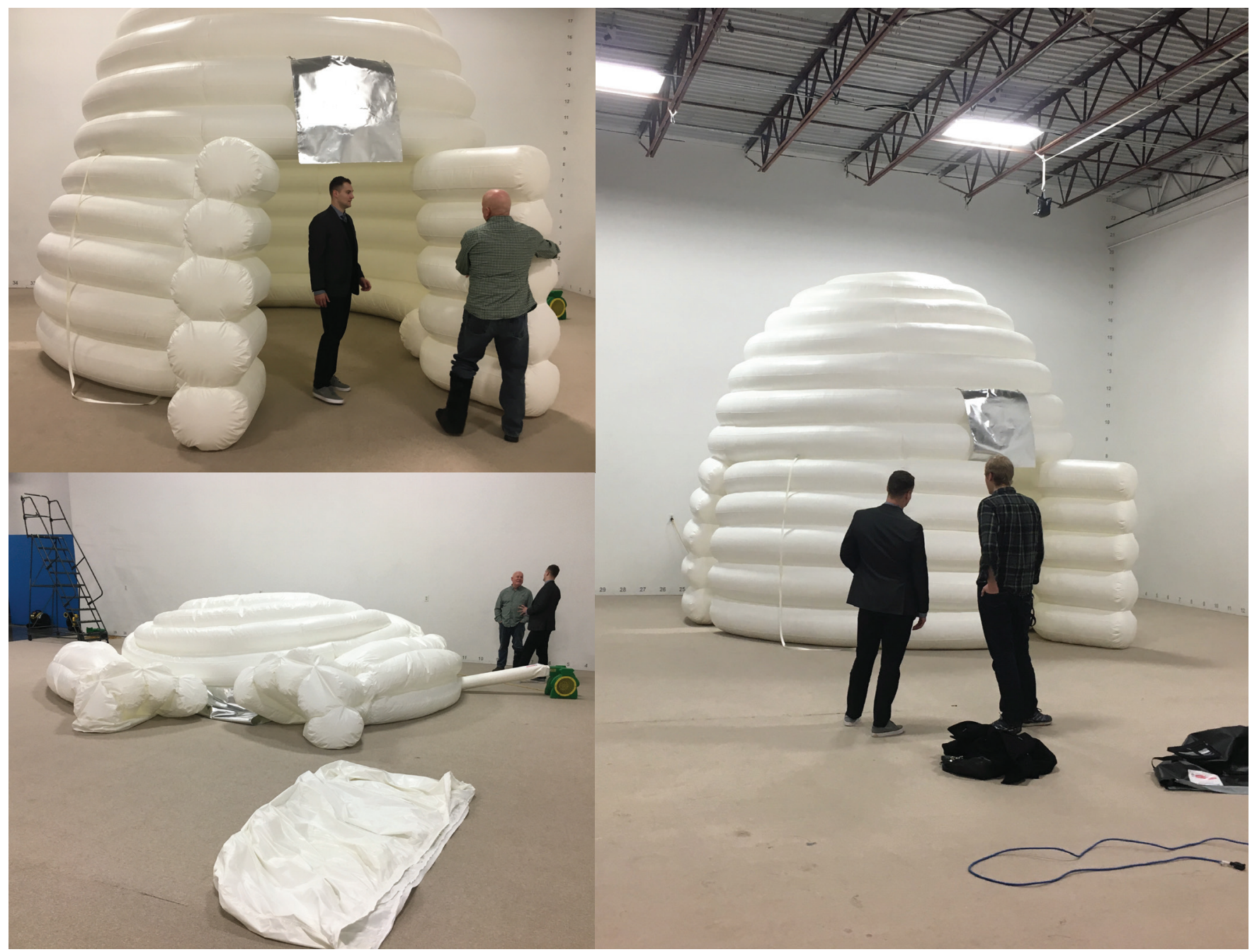

Figure 3: Test inflation of The Warming Hive at Landmark Creations near Minneapolis, Minnesota on January 5, 2017. The pneumatic inflates in under three minutes, and is powered by two portable blowers (one inflates the enclosure, and the other inflates the interior bench). Weighing under 200 pounds, The Warming Hive packs up into a bag and can easily be transported by car to a selected site and installed by two people. Photos by author.

new technologies, Price was continually searching for ways to redesign the built environment as an adaptive and interactive infrastructure that could anticipate the changing needs of society. He was less interested in buildings-Price deemed them fixed, static, inflexible and obsolete-and more intent on structures that could anticipate future change and use. ${ }^{2}$ This is why, starting in the early 1960s, he worked to bring attention to the potential of "air," which until then had been mostly invisible to architecture. The near instantaneity and perceived instability of air structures led Price to dedicate years of his practice to their development and regulation. ${ }^{3}$ A champion of "anticipatory design," ${ }^{\text {" }}$ Price referred to air structures as "valuable distorters of time, place and frequency for social advantage."

\section{THE PROJECT}

One of the most culturally, ethnically, and religiously diverse neighborhoods in Milwaukee, Riverwest is currently experiencing a renaissance. According to a local anthropologist, the art scene is playing a key role in this transformation:

But in Riverwest, art rules. And the art forms are as diverse as the people. The issues that united the major Riverwest cultural groups back in the 1960s and 1970s-fair housing, cultural tolerance, peace, and social justice-continue to be championed in the neighborhood. Art is routinely used to advance social causes, and a sense of civic responsibility is often reflected in the art forms. ${ }^{6}$

For example, The Open, a Riverwest gallery founded in 2017 by a collection of local artists, promotes diversity in both the arts and its community. The gallery is a "project platform housing several programs": Nicholas Frank Public Library (NFPL), Microlights, The Oven, The Outlet, and Designers Talking Library. ${ }^{7}$ Three of these artists (Nicholas Frank, John Riepenhoff, and Katy Cowan), and their respective curatorial platforms (NFPL, The Oven, and The Outlet), served as not 


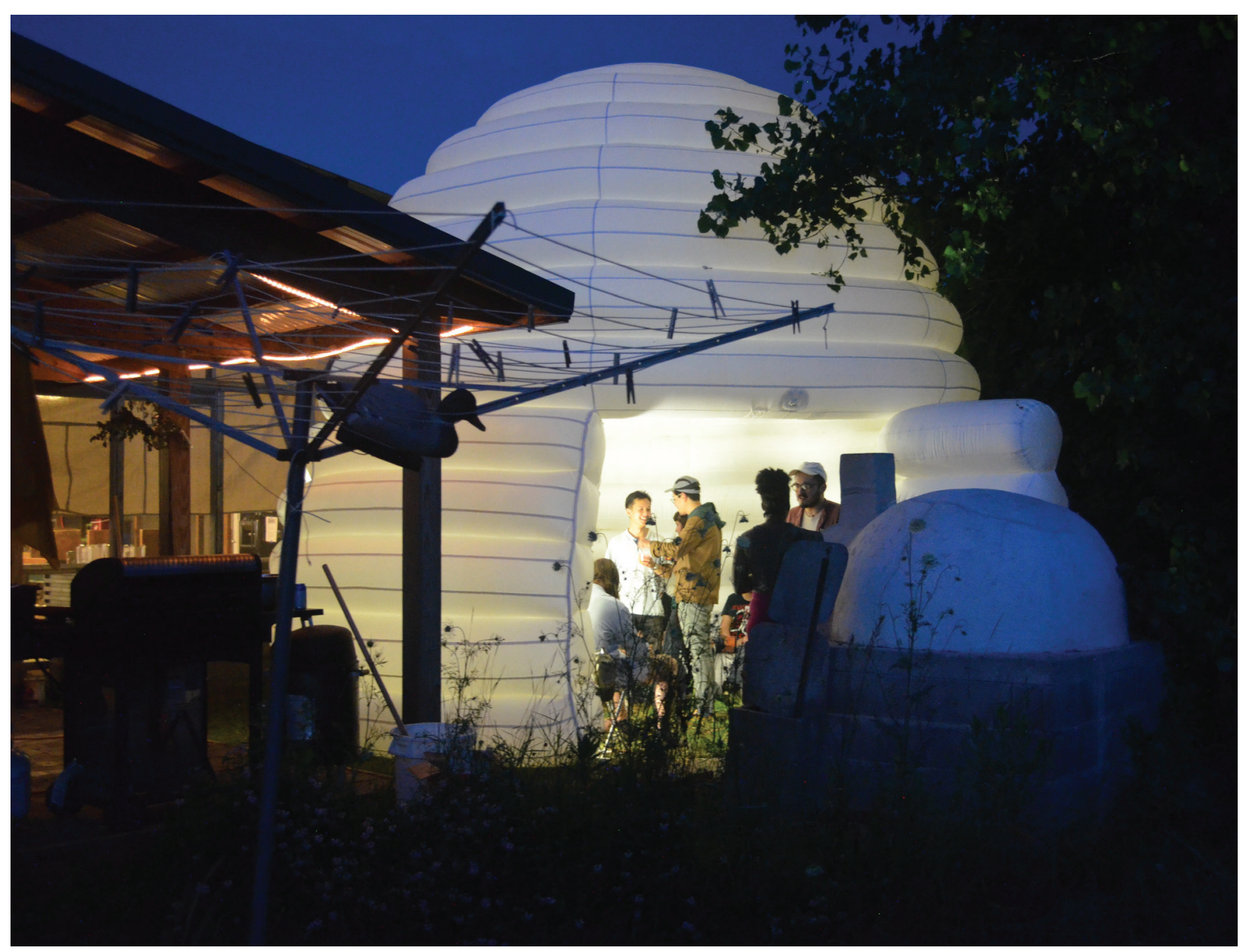

Figure 4: Installation of The Warming Hive at ACRE Residency in Steuben, Wisconsin on July 11, 2017. Milwaukee-based artist Sara Caron mixed up craft cocktails inside the inflatable for visiting artists as part of her Bermuda Triangle pop-up bar project. Earlier in the day, a few artists from Japan collaborated with John Riepenhoff to cook mochi in an outdoor oven (pictured far right),around which the pneumatic was installed. Photo by author.

only the hosts for The Warming Hive project, but likewise its clients and collaborators.

In Fall 2016, working in close collaboration with these three artists, eleven undergraduate and graduate architecture students at University of Wisconsin-Milwaukee School of Architecture and Urban Planning (UWM-SARUP) - taught by Assistant Professor Whitney Moon-designed, prototyped, and fabricated The Warming Hive, an inflatable installation which premiered on April 1, 2017 at The Open. As part of an architectural seminar entitled Pillow Talk: "Blow Up!", the project was conceived as an opportunity for students to not only design and realize a pneumatic construction, but to engage directly with their community. By actualizing a temporary installation, which could then be deployed in different locations for a variety of year-round uses, students demonstrated the capacity for airsupported structures to generate social resilience by catering to a wide-array of site conditions and programmatic demands.
Because The Open is comprised of several curatorial platforms, the objective of this temporary architectural installation was to engage multiple programs simultaneously, while providing an outdoor gathering space for gallery visitors during events. At the request of Frank, Riepenhoff, and Cowan, students were directed to consider a range of installation proposals that could accommodate this request to define a social space for the gallery. The Warming Hive-one of three group proposals put forth by the students-not only responded to the clients' request, but also explored the capacity for the outdoor installation to operate year-round, particularly in winter months. By providing a gathering space that was hospitable in sub-freezing temperatures and snow, this temporary pneumatic shelter could be deployed on an as needed basis. In addition to being "plugged-in" to The Outlet-an electrical outlet curated by Cowan inside the gallery-The Warming Hive was designed to engage, both thermally and socially, The Oven-an outdoor brick oven run by Riepenhoff. 


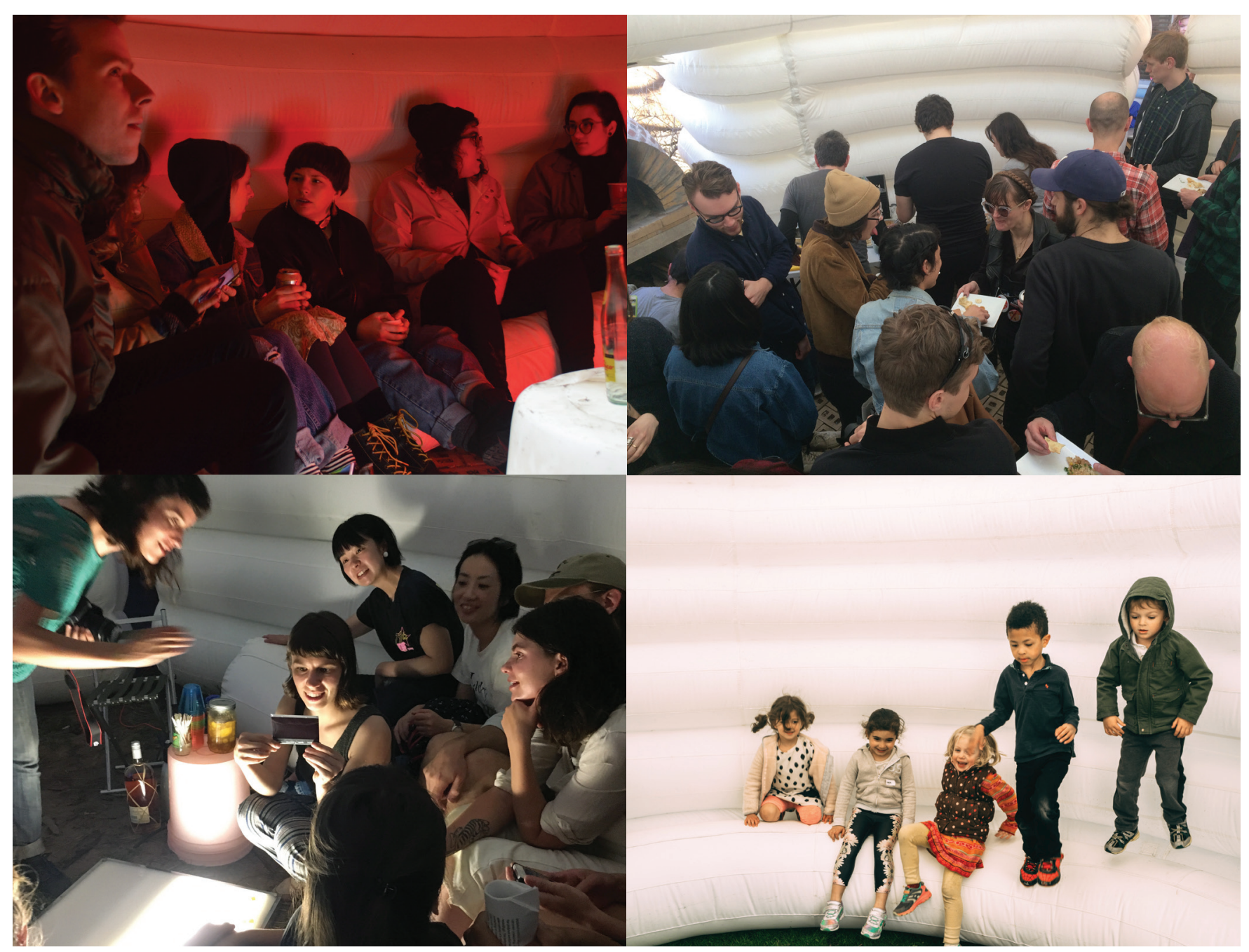

Figure 5: Four different inflations of The Warming Hive in 2017 demonstrating social resilience through community engagement. Capable of being deployed in both urban and rural settings, the pneumatic enclosure provides a gathering and recreation space for all ages, any time of day or night. Photos by author.

Because this winning proposal-selected by the artists/clients and visiting critics-directly engaged with a heat source, it needed to comply with life safety concerns and code regulations. That is, the pneumatic structure needed to be both fireproof and durable. Due to these constraints, it was not an option to work with typical DIY inflatable materials like plastic sheeting, Mylar and nylon. Fabricated by Landmark Creations in Minnesota using flame retardant $8.5 \mathrm{oz}$. vinyl coated white nylon, this structure inflates in under three minutes, and is able to have a lifespan of $10+$ years, rather than days, changing the typical perception of pneumatics structures as disposable, wasteful, and unreliable.

The Warming Hive realizes a collaborative student research and design project exploring pneumatic technology in relationship to mobility, sociability, environmental responsibility, and pedagogical advancement. Adaptable to a variety of site and seasonal conditions, this dome-like air-filled structure offers capabilities of implementation and transportation that cannot be matched by traditional construction: it is inflated in under three minutes, weighs under 200 pounds, and can be easily packed up and transported to various locations. Designed with built-in pneumatic seating and an insulated, fireproof and projectionfriendly skin, The Warming Hive provides a comfortable year-round shelter for exhibition, cooking and gathering.

In addition to its mobility, flexibility, and near instantaneous deployment, The Warming Hive offers unlimited potential for generating social resilience in the built environment. Although initially designed for a specific site and use, The Warming Hive was conceived as a prototypical nomadic structure: it can be deployed for a variety of temporary and event-based uses, is affordable $(\$ 5,0000)$, and can easily be reproduced and/or modified. Powered by two portable blowers, the double-membrane structure (14ft high by $16.5 \mathrm{ft}$ diameter) can comfortably accommodate twenty or more people, facilitating social interaction and providing protection from the elements (sun, wind, rain, etc.). In 
addition to an inflated bench, the enclosure features an oculus at the top of the dome, which allows hot air to escape through stack ventilation, and provides a visual connection to the sky. Likewise, two entries-one with interchangeable pneumatic "doors" (utilizing zippers and Velcro)-allow for customization of layout, flexibility of use, and enhanced accessibility and visibility.

The Warming Hive has been deployed ten times at seven different locations throughout Wisconsin. In addition to hosting three separate art opening events at The Open, and being inflated multiple times at UWM-SARUP, the pneumatic enclosure has been invited to several venues including: an art auction at the Green Gallery in Milwaukee, an artist residency at ACRE in Steuben, the Makeshift Festival in Madison, and a community event at the John Michael Kohler Arts Center in Sheboygan. In all but one of these cases, the requests to utilize The Warming Hive have been pro-bono, meaning that the instructor and one or more students have assumed the responsibility to coordinate its installation, as well as donated their time and labor. It was important to both the artist collaborators (Frank, Riepenhoff \& Cowan), as well as the instructor and seminar students, that the project be made available to the greater community on an as-needed basis.

Each inflation of The Warming Hive offers an opportunity to test its technical and social performance with respect to variable site and programmatic conditions. In addition to offering a structurally sound temporary space for numerous kinds of activities, the pneumatic installation continually offers delight to users of all ages. As a constructed prototype which continues to be tested in a variety of contexts, including utilization during all four seasons, The Warming Hive demonstrates the potential for pneumatic architecture to facilitate social resilience in the 21 st century. To date, The Warming Hive continues to be inflated upon request.

Project: The Warming Hive

Size: $14 \mathrm{ft}$ high by $16.5 \mathrm{ft}$ diameter

Material: Flame retardant $8.5 \mathrm{oz}$. vinyl coated white nylon.

Fabricator: Landmark Creations, Burnsville, $\mathrm{MN}$

Inflation Time: 2.5 minutes

Cost: $\$ 5,000$

Instructor: Assistant Professor Whitney Moon, PhD, RA

Student Designers: Jordan Nelson (Project Lead), Trevor Georgeson, Jackson Leverenz, Sean Mroczkowski, Jordan Nelson, Ryan Neidinger, Brandon Sather, Thomas Sebastian, Sam Smith, Indhumathi Venkatachalam, Yangtian Yin, and John Young.

Clients/Collaborators: Nicholas Frank (Nicholas Frank Public Library), John Riepenhoff (The Oven \& Green Gallery), \& Katy Cowan (The Outlet).

Donors: Wendel Chamberlin (UWM-SARUP '76), Chipstone Foundation, Design Fugitives, and Pacific Construction Co.

\section{ENDNOTES}

1. See Cedric Price, Archigram 3, 1963. It should be noted that in 1966, Price and Newby approached the British Ministry of Technology with proposals to conduct research on the use of air structures in the construction industry. As a result, the British Ministry of Public Building and Works commissioned them to undertake a survey on pneumatics in 1968. Their extensive research on the topic was published as a report entitled Air Structures: A Survey in 1971 and it covered the history, principles and applications of air structures. Although the British Government did not sponsor further research on the topic, what was particularly remarkable about this endeavor was Price and Newby's commitment to both the technological and cultural dimensions of inflatables. According to Price and Newby, the publication "surveys the current research and development in this field and makes a number of proposals for future research." Cedric Price and Frank Newby, Air Structures: A Survey (London: Her Majesty's Stationery Office, 1971) iii.

2. In an issue of Archigram dedicated to self-sustained and portable environments, Price writes "the value of permanence must be proven not merely assumed." Cedric Price, "Insert 25", Archigram 8-Popular Pak, 1968.

3. Notes by Cedric Price, for a keynote speech delivered on 01 June 1973 at the Air Structures in Education conference in Columbia, Maryland. See Samantha Hardingham, Cedric Price Works, Volume 2: Articles and Talks (London: Architectural Association / Montreal: Canadian Center for Architecture, 2017) 211.

4. "The first thing to bear in mind when contemplating Price's work is that his central field of enquiry was what he called 'anticipatory design', an approach which is concerned with the importance of defining a question rather than solving a problem-on the basis that architecture is too slow for problemsolving-and which produces architecture that is specifically designed to expect change." Hardingham, Cedric Price Works, Volume 1: Projects (London: Architectural Association / Montreal: Canadian Center for Architecture, 2017) 14.

5. Notes by Cedric Price, for a keynote speech delivered on 01 June 1973 at the Air Structures in Education conference in Columbia, Maryland. See Hardingham, Cedric Price Works, Volume 2: Articles and Talks, 211.

6. http://www.neighborhoodsinmilwaukee.org/Riverwest.pdf (Accessed August 10, 2018).

7. https://www.nicholasfrankpubliclibrary.org (Accessed August 10, 2018). 